\title{
$\beta$-Galactosidase Activity and Lactose Utilization in Aspergillus nidulans
}

\author{
By P. A. FANTES* AND C. F. ROBERTS \\ Department of Genetics, The University, Leicester, LEI $7 R H$
}

(Received 5 February 1973)

\begin{abstract}
SUMMARY
When mycelia of Aspergillus nidulans are grown with lactose or galactose as the carbon source, $\beta$-galactosidase activity is induced at least 30 -fold. The effect of growth conditions on the formation of the activity was investigated.

The enzyme has been partially characterized: two proteins with molecular weights near I 20000 and 450000 have $\beta$-galactosidase activity; present evidence suggests that these are different aggregates of the same polypeptide.

A mutant, laci5o, is described which grows poorly on lactose and lacks $\beta$ galactosidase activity. These two characters are determined by two unlinked genes and independently expressed. This demonstrates the existence of an alternative (and unknown) mode of lactose utilization. Although $\beta$-galactosidase activity is not required for mycelial growth on lactose, it is essential for germination of conidia with lactose as the sole carbon source.

Mutants unable to form $\beta$-galactosidase activity fall into three genetic groups designated $b g a A, B$ and $C$. All these mutants grow normally with lactose as sole carbon source. One mutant at the $b g a A$ locus forms a heat-labile $\beta$-galactosidase and is presumably a structural gene lesion.
\end{abstract}

\section{INTRODUCTION}

In many micro-organisms $\beta$-galactosidase activity is induced by lactose in the growth medium. This occurs in certain species of Staphylococcus and Streptococcus (McKay, Walter, Sandine \& Elliker, 1969), as well as in the better known instance of Escherichia coli. In the ascomycete Neurospora crassa two $\beta$-galactosidases occur which have different $\mathrm{pH}$ optima, are differentially induced (Bates, Hedman \& Woodward, I967) and are physically separable (Bates \& Woodward, 1964). One of these enzymes occurs in both an intracellular and an extracellular form (Johnson \& DeBusk, I970). In Aspergillus nidulans, $\beta$-galactosidase activity is induced by lactose, but only one enzyme, an intracellular species, has been reported (Paszewski, Chojnacki, Litwinska \& Gajewski, 1970).

Only in Escherichia coli has it been shown that the enzymatic activity is necessary for lactose utilization (Jacob \& Monod, I96I). No mutants lacking $\beta$-galactosidase and unable to utilize lactose have been isolated in Neurospora crassa, presumably because of the two enzymes (Bates \& Woodward 1964).

When this work began, two series of lac mutants of Aspergillus nidulans had been described. Roberts ( $1963 a$ ) isolated seven mutants which grew poorly with lactose as sole carbon source; these were assigned to two loci, lacA and lacB. Evidence presented below and elsewhere (Gajewski, Litwinska, Paszewski \& Chojnacki, 1972) shows that neither

* Present address: Mikrobiologisches Institut, Eidg. Technische Hochschule, Universitätstrasse 2, 8006 Zürich, Switzerland. 
$\operatorname{lac} A$ nor $l a c B$ is the structural gene for $\beta$-galactosidase. A second series of mutants was obtained by Gajewski \& Litwinska (1969), who reported that mutations at a number of loci led to an inability to form $\beta$-galactosidase. The majority of their mutants (called lac 5 to lac32) were 'leaky', that is, showed slight growth on lactose, and those not able to grow at all also showed defective growth on unrelated carbon sources such as acetate or other organic acids. The situation appeared to be more complex than in Escherichia coli, raising the possibility that two $\beta$-galactosidases might be present. If this were the case it is unlikely that mutants of $A$. nidulans lacking $\beta$-galactosidase would be obtained by screening for poor growth on lactose.

A histochemical technique for detecting $\beta$-galactosidase activity in colonies grown on solid medium was used to screen for mutants lacking $\beta$-galactosidase. Evidence is presented which suggests that there is a single $\beta$-galactosidase enzyme in Aspergillus nidulans. The colony staining technique has shown that $\beta$-galactosidase activity is not essential for growth of the organism with lactose as sole carbon source, and that there is an alternative (and unknown) metabolic pathway for utilization of this sugar. The structural gene for $\beta$-galactosidase in $A$. nidulans has been identified.

\section{METHODS}

Organisms. The translocation-free strains R2I ( pabaAI yA) and RI53 (wA3; pyroA4) were from our stock collection. The 'master' strain used for mitotic analysis was R87 (FGSC I05), with genotype biAI; AcrAI wA3; phenA2; pyroA4; lysB5; sB3; nicB8; co (Barratt, Johnson \& Ogata, 1965). The carbohydrate mutants FGSCOIO3 (yA2; pyroA4; lacAI), FGSCOIO4 (biAI; $w A 3$; lacB3) were obtained from the Department of Genetics, University of Glasgow; R9 (biAI; wA3; galE34), which is galactokinaseless, and the corresponding wild-types R2 (biAI; wA3) and RI43 (yA2; pyroA4) were from our collection (Roberts, I $963 a$ ).

Media and general methods of culture. These were broadly as described by Roberts ( $1963 b)$. Carbon sources were added to minimal medium after autoclaving separately. Final concentrations were: glycerol, $0.04 \mathrm{M}$; casamino acids (Difco), I \% (w/v); nutrient broth (Oxoid no. 2), $2.5 \%(\mathrm{~W} / \mathrm{v})$; D-glucose, D-galactose, lactose, sucrose, L-arabinose and D-xylose, $0.02 \mathrm{M}$.

Aspergillus nidulans was grown at $37^{\circ} \mathrm{C}$, unless otherwise stated.

Genetic analysis. The techniques used follow those of Pontecorvo, Roper, Hemmons, MacDonald \& Bufton (I953). Mitotic haploidization induced by $p$-fluorophenylalanine (Lhoas, 196I) was used for assignment of genes to linkage groups (Forbes, 1959).

Detection of $\beta$-galactosidase activity in colonies grown on agar medium. The chemical principle of the method is described by Burstone (I962).

After inoculation of conidia onto solid medium, a sterile filter paper $(9 \mathrm{~cm} \mathrm{diam}$.) was placed in contact with the surface. Colonies were allowed to grow to a diam. of 15 to $20 \mathrm{~mm}$, when the filter paper was removed, stripping the non-wettable conidia from the colonies in the process. To each plate was added $4 \mathrm{ml}$ of sodium phosphate buffer $(0.5 \mathrm{M}, \mathrm{pH} \mathrm{8.3})$ containing I part in 20 of a methanolic solution of 6-bromo-2-naphthyl- $\beta$-D-galactopyranoside $(8 \mathrm{mg} / \mathrm{ml})$. The plates were incubated at $37^{\circ} \mathrm{C}$ for 2 to $4 \mathrm{~h}$, and excess substrate decanted. The surface of each plate was then covered with an aqueous solution of Fast Blue $B$ Salt $(5 \mathrm{mg} / \mathrm{ml})$ and examined after ro min. $\beta$-Galactosidase activity is indicated by an intense purple stain localized in the mycelium of the colony.

Isolation of mutants. The mutagen was $N$-methyl- $N$-nitro- $N^{\prime}$-nitrosoguanidine (NMG), 
following the procedure of Alderson \& Hartley (I969). The proportion of survivors ranged from $0.1 \%$ to $3 \%$.

In the isolation of lac mutants, conidia were plated on MM glucose for 5 days, replicated to MM lactose, and the plates scored after 2 days.

In the isolation of mutants affected in $\beta$-galactosidase formation, mutagenized conidia were plated directly onto either glycerol + galactose (for $\beta$-galactosidase negative mutants) or glycerol (for constitutive mutants). After incubation (4 days) and staining, the desired colonies were retained by cutting out of the medium and transferring to complete medium. Few $(<5 \%)$ possible mutants were lost by this procedure.

Preparation of cell-free extracts. Mycelium was harvested from liquid culture by suction onto filter paper, washed with distilled water, and washed again with cold sodium phosphate buffer $(0.05 \mathrm{M}, \mathrm{pH} 7.0$ ) containing I mm-magnesium chloride (extraction buffer). Mycelia were either stored at $-20{ }^{\circ} \mathrm{C}$ for up to 2 weeks, or used immediately to prepare cell-free extracts. No loss of activity was observed in deep-frozen mycelia.

Extraction of mycelium was carried out by one of two methods. (i) By ultrasonic disintegration for $30 \mathrm{~s}$ with a $150 \mathrm{~W}$ MSE Ultrasonic Disintegrator, operating at $20 \mathrm{kHZ}$, peak-to-peak amplitude I $5 \mu \mathrm{m}$. The mycelium was suspended in extraction buffer and held at $0{ }^{\circ} \mathrm{C}$ throughout. Protein concentrations obtained were between 0.5 and $3 \mathrm{mg} / \mathrm{ml}$. (ii) By freezing the mycelium at dry-ice temperature and extruding through a small exit hole in a pressure cell, operating at up to 12 tons (Mandell \& Roberts, I966). The extruded material was allowed to thaw in extraction buffer. Protein concentrations up to $20 \mathrm{mg} / \mathrm{ml}$ were obtained.

Debris was removed by centrifugation at $27000 \mathrm{~g}$ for $10 \mathrm{~min}$ at $2{ }^{\circ} \mathrm{C}$.

The method of extraction did not affect the specific activity of $\beta$-galactosidase obtained from the same batch of mycelium.

Assay of $\beta$-galactosidase activity. (i) Assays were run at $25{ }^{\circ} \mathrm{C}$ with $o$-nitrophenyl- $\beta$-Dgalactopyranoside (ONPG) as substrate, after the method of Wallenfels (I962). Each reaction mixture contained: sodium phosphate (0.05 $\mathrm{M}, \mathrm{pH} 7.6$ ), I.5 ml; $\mathrm{MgCl}_{2}$ (0.0I M), $0.3 \mathrm{ml}$; ONPG (0.01 M), $0.3 \mathrm{ml}$; enzyme preparation, $0.3 \mathrm{ml}$; water to $3.0 \mathrm{ml}$. A blank without ONPG was run for each assay. The reaction was stopped after Io min by the addition of $\mathrm{I} \mathrm{ml}$ of $\mathrm{I} \mathrm{M}-\mathrm{K}_{2} \mathrm{CO}_{3}$. The absorbance at $420 \mathrm{~nm}$ was measured in a Gilford $300-\mathrm{N}$ Micro-sample spectrophotometer. (ii) When an accurate estimate of the initial reaction rate was required, for assaying possible temperature-sensitive enzyme, a continuous assay was performed in a $\mathrm{I} \mathrm{ml}$ cuvette. All volumes were reduced in proportion. The absorbance at $420 \mathrm{~nm}$ was followed in a Unicam SP I 800 recording spectrophotometer.

Lactose hydrolysis was measured using a similar reaction mixture to that in (i) above, with $0.1 \mathrm{M}$-lactose instead of $0.01 \mathrm{M}$-ONPG. The reaction was stopped by heating to $100^{\circ} \mathrm{C}$ for 2 min. After cooling, the amount of glucose released was estimated using a glucose oxidase-peroxidase coupled system (Sigma Chemical Co., St Louis, Missouri, U.S.A.).

Protein estimation was done by the method of Lowry, Rosenbrough, Farr \& Randall (195I), using bovine serum albumin (Sigma) as standard.

Sources of reagents. ONPG was obtained from the Sigma Chemical Co., as was Fast Blue B Salt (practical grade), the enzyme kit (no. 5Io) for glucose determination, and bovine liver catalase. Fast Black K Salt and 6-bromo-2-naphthyl- $\beta$-D-galactopyranoside were obtained from Koch-Light, Colnbrook, Buckinghamshire. Other reagents were of analytical grade. 


\section{RESULTS}

\section{Properties of $\beta$-galactosidase}

During growth of Aspergillus nidulans on lactose or galactose, $\beta$-galactosidase activity is formed, as defined by the ability to hydrolyse $o$-nitrophenyl- $\beta$-D-galactopyranoside (ONPG). Under the assay conditions described the enzyme activity is nearly proportional to the amount of enzyme preparation assayed, although at low concentrations of protein the activity decreases disproportionately. The time-course of the reaction is not strictly linear, the non-linearity being more marked at $37^{\circ} \mathrm{C}$ than at $25^{\circ} \mathrm{C}$. To reduce error from these causes, assays were run for $10 \mathrm{~min}$ at $25^{\circ} \mathrm{C}$, and generally the amount of protein assayed was between 0.15 and $0.75 \mathrm{mg}$.

The variation of $\beta$-galactosidase activity with $\mathrm{pH}$ was investigated. When the assay was performed at $25^{\circ} \mathrm{C}$ with ONPG as substrate, an uneven plateau that could represent a biphasic variation was found (Fig. I). This result, together with the complexity of the genetic data available, suggested that two $\beta$-galactosidase enzymes might be present, as in Neurospora crassa. These presumed enzymes would have $\mathrm{pH}$ optima near $7 \cdot 6$ and $9 \cdot 0$. At first, assays were performed at both these $\mathrm{pH}$ values, and the ratio of the two activities determined. No alteration in this ratio (near to unity) was found under any of the growth conditions tested, and the likelihood of differential induction of two enzymes thus appeared small. The $\beta$-galactosidase activities quoted in this report were all measured at $\mathrm{pH} 7 \cdot 6$.

To partially characterize the protein with $\beta$-galactosidase activity, crude extracts were subjected to various fractionation procedures. Two techniques showed the existence of two molecular species of $\beta$-galactosidase - gel chromatography on Sepharose 6-B (Fig. 2) and sucrose gradient sedimentation (Fig. 3). The latter technique was used to estimate the mol. wts of the enzyme species, using catalase $(M=230000$ daltons; Sumner \& Gralen, 1938) as a marker. The mol. wts were estimated to be 120000 and 450000 daltons by the method

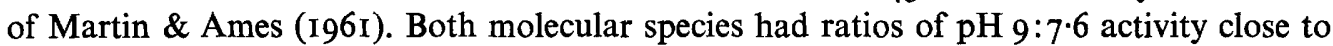
that of a crude extract. The mol. wts suggest a monomer-tetramer relationship.

Detailed investigation of the $\beta$-galactosidase proteins was precluded by irreversible loss of activity on dialysis: this also occurred when other techniques which lead to loss of small molecules were applied. Addition of the dialysate to an inactive dialysed extract did not restore the activity; nor did inclusion in the dialysis buffer of dithiothreitol, ethylenediaminetetra-acetic acid, or magnesium ion prevent the loss.

\section{Growth conditions for formation of $\beta$-galactosidase}

The growth of Aspergillus nidulans on the various carbon sources is as follows: D-glucose, sucrose and glycerol are good carbon sources, giving strong growth; lactose and D-galactose are poor; Casamino acids, nutrient broth, D-xylose and L-arabinose are intermediate. With mixtures of two carbon sources, growth is as strong as that given by the better component. Mycelia of the wild-type strain R2 I were grown in liquid MM with the above carbon sources, and on certain mixtures. Cell-free extracts were assayed for $\beta$-galactosidase activity (Table I).

Lactose- and galactose-grown mycelia contained 30 times as much $\beta$-galactosidase activity as mycelia grown on most other carbon sources. Growth on L-arabinose led to slight induction of the activity, possibly because of its structural similarity to D-galactose. The amount of $\beta$-galactosidase present after growth on mixtures of carbon sources was also determined (Table I). Induction of the enzyme by lactose was prevented by the presence of any other carbon source, in contrast to the induction by galactose in the presence of glycerol or casamino acids. Decreasing the glycerol concentration to $0.01 \mathrm{M}$ in a glycerol-lactose 


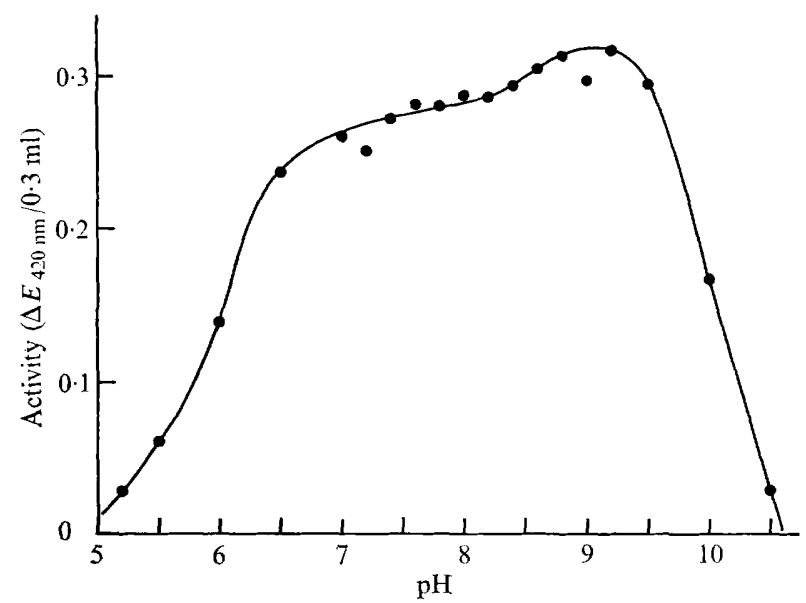

Fig. I. Variation of $\beta$-galactosidase activity with $\mathrm{pH}$. Mycelium of strain R2I was grown in MM galactose at $37^{\circ} \mathrm{C}$ for $36 \mathrm{~h}$, and extracted by ultrasonication. The buffer system used contained tris (hydroxymethyl) aminomethane, maleic acid, and glycine, each at $50 \mathrm{~mm}$. The $\mathrm{pH}$ was adjusted to a series of values between 5.2 and 10.5 with concentrated $\mathrm{NaOH}$ solution. Assays were performed otherwise as described under Methods. The error in the assay is less than $5 \%$.

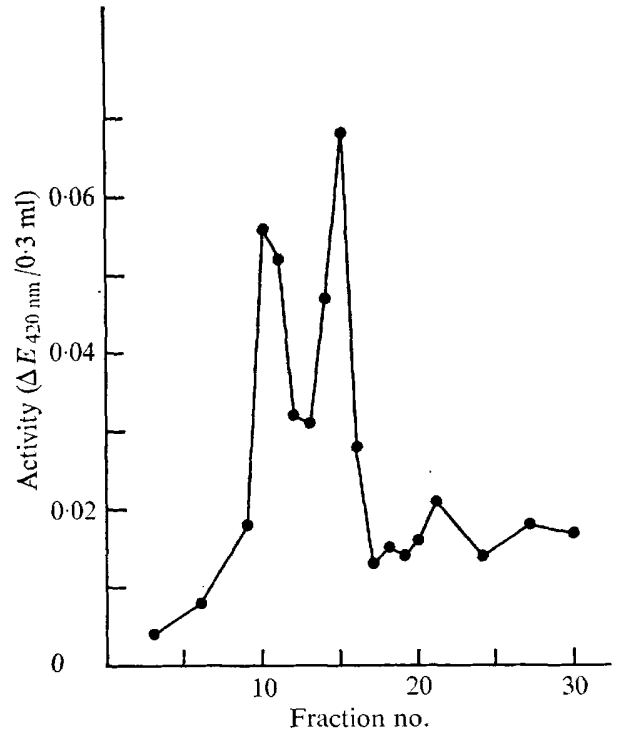

Fig. 2

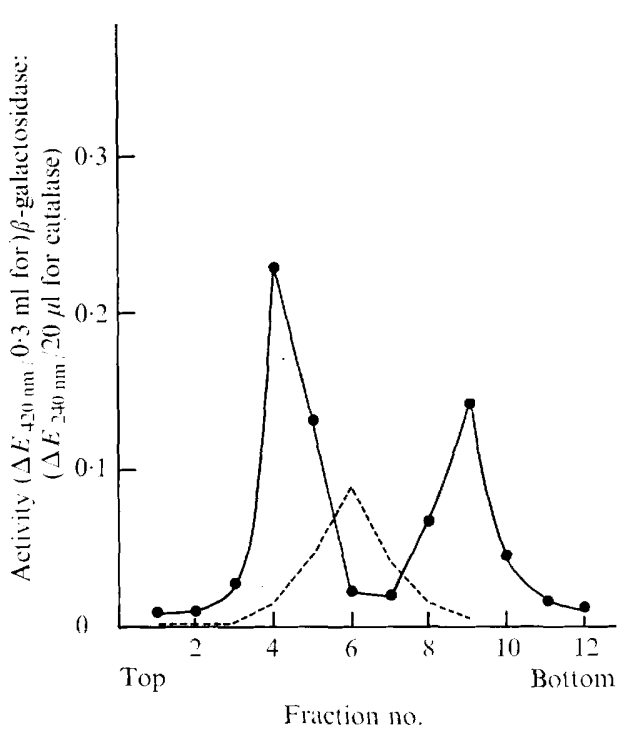

Fig. 3

Fig. 2. Gel chromatography of $\beta$-galactosidase activity from Sepharose $6 \mathrm{~B}$. The column $(\mathrm{I} \cdot \mathrm{I} \times 26 \mathrm{~cm})$ was equilibrated with extraction buffer at $4^{\circ} \mathrm{C}$. A crude extract containing $10 \cdot 95 \mathrm{mg}$ protein $/ \mathrm{ml}$ was made from R2 I mycelium grown for $36 \mathrm{~h}$ in MM+galactose. A sample ( $3 \mathrm{ml}$ ) was applied to the column, which was then eluted with extraction buffer. Fractions ( $2 \mathrm{ml})$ were collected and assayed for $\beta$-galactosidase activity. Recovery of the activity was I I \%

Fig. 3. Sedimentation of $\beta$-galactosidase activity in a sucrose gradient. Linear sucrose gradients $(5 \%$ to $20 \%$ sucrose in extraction buffer) were prepared using a Buchler gradient maker. The final volume of each gradient was $12.0 \mathrm{ml}$ in a $3 \frac{3}{4} \times \frac{8}{16}$ inch tube. The sample applied to the gradient contained $0.9 \mathrm{ml}$ crude extract in $5 \%$ sucrose (from R2I mycelium grown for $36 \mathrm{~h}$ in MM galactose), and $0.1 \mathrm{ml}$ catalase $(2 \mathrm{mg} / \mathrm{ml})$. Centrifugation was at $I 12000 \mathrm{~g}$ (30 krev./min in the SW 40-Ti rotor of a Beckman L 2-65 B ultracentrifuge) for $16 \mathrm{~h}$ at $2{ }^{\circ} \mathrm{C}$. Fractions ( $\mathrm{I} \mathrm{ml}$ ) were collected by upward displacement using a density-gradient fractionator (Isco, Model I 80). Each fraction was assayed for $\beta$-galactosidase and catalase activity. A $20 \mu \mathrm{l}$ sample was added to $3 \mathrm{ml}$ of $\mathrm{H}_{2} \mathrm{O}_{2}$ diluted in extraction buffer to give an absorbance at $240 \mathrm{~nm}$ of 0.6 . The rate of decrease of absorbance at this wavelength was followed in a Unicam 1800 Recording Spectrophotometer. Catalase activity is shown by the broken line. 


\section{Table I. Specific activities of $\beta$-galactosidase in mycelia grown on different carbon sources}

Strain R2I was grown at $37{ }^{\circ} \mathrm{C}$ in liquid MM with the carbon sources shown. Mycelia were extracted by ultrasonic disintegration, and assayed for $\beta$-galactosidase activity.

\section{Carbon source}

Sucrose $(0.02 \mathrm{M})$
D-Glucose $(0.02 \mathrm{M})$
Glycerol $(0.04 \mathrm{M})$
Lactose $(0.02 \mathrm{M})$
D-Galactose $(0.02 \mathrm{M})$
L-Arabinose $(0.02 \mathrm{M})$
D-Xylose $(0.02 \mathrm{M})$
Casamino acids $(\mathrm{I} \%, \mathrm{w} / \mathrm{v})$
Nutrient broth $(2.5 \%$, w/v)
D-Glucose* + lactose*
D-Glucose + D-galactose
Glycerol + lactose
Glycerol + D-galactose
Casamino acids + lactose
Casamino acids + D-galactose
Nutrient broth + lactose
Nutrient broth + D-galactose

* Concentrations as for single carbon sources throughout.

Specific activity of $\beta$-galactosidase (nmole/min/mg protein)

$<0.2$

$<0.2$

$<0.2$

6.0

$17 \cdot 7$

$\mathrm{I} \cdot \mathrm{O}$

$<0.2$

$<0.2$

$<0.2$

$<0.2$

0.3

$<0.2$

$5 \cdot 5$

$<0.2$

I. I

0.3

0.6

$(0.02 \mathrm{M})$ mixture did not lead to $\beta$-galactosidase formation. Perhaps other carbon compounds are taken up in preference to lactose, which is rather a poor carbon source. It is not likely that catabolite repression is preventing induction, as a non-glycolytic carbon source such as Casamino acids still shows this effect.

The $\mathrm{pH}$ of the growth medium has been reported to affect $\beta$-galactosidase formation in Neurospora crassa (Bates et al. 1967), and this was investigated in Aspergillus nidulans. The $\mathrm{pH}$ of the medium has little effect on $\beta$-galactosidase formation when the carbon source is lactose, but a marked effect is found after growth with galactose (Table 2).

An effect of $\mathrm{pH}$ of the growth medium on galactose utilization has been reported by Roberts (I970); in addition to the Leloir pathway via uridine diphospho-galactose, a second pathway exists whose nature is unknown. The Leloir pathway operates in Aspergillus nidulans only when the $\mathrm{pH}$ of the growth medium is low: this is shown by direct measurement of the galactokinase levels in the wild-type, and by the observation that mutants defective in the pathway grow as well as wild-type on galactose at $\mathrm{pH}$ values above 7 , despite severely restricted growth at $\mathrm{pH}_{5}$.

To investigate further the effect of galactose metabolism on $\beta$-galactosidase formation, the induction of the enzyme in a galactokinaseless mutant (galE) was measured. The mutant grew well on both lactose and galactose. (Since the medium was initially at $\mathrm{pH} 6.5$ the mutant grew well on galactose. It lacks galactokinase irrespective of $\mathrm{pH}$.) The results (Table 3) show that induction in this strain is as effective as in the wild-type. Thus operation of the Leloir pathway is not required for $\beta$-galactosidase formation, but it seems likely that the second galactose pathway is involved in induction by galactose (see below).

The mutants lacAI and lacB3 (Roberts, 1963a) grow well on galactose and possess $\beta$-galactosidase activity (Table 3 ). Both strains had similar activities when assayed at 
Table 2. Effect of growth at different $p H$ on $\beta$-galactosidase formation

Experimental conditions were as in Table I except that growth media were buffered with tris-maleate $(0.05 \mathrm{M})$.

\begin{tabular}{|c|c|c|c|c|}
\hline \multirow[b]{2}{*}{ Carbon source } & \multicolumn{2}{|c|}{$\mathrm{pH}$ of medium } & \multirow{2}{*}{$\begin{array}{l}\text { Incubation } \\
\text { time } \\
\text { (h) }\end{array}$} & \multirow{2}{*}{$\begin{array}{c}\text { of } \beta \text { - } \\
\text { galactosidase } \\
\text { (nmole/min } / \mathrm{mg} \\
\text { protein) }\end{array}$} \\
\hline & Initial & Final & & \\
\hline Sucrose & $\begin{array}{l}5 \cdot 0 \\
6 \cdot 5 \\
7 \cdot 5\end{array}$ & $\begin{array}{c}- \\
7 \cdot 01 \\
7 \cdot 36\end{array}$ & $\begin{array}{l}22 \\
22 \\
22\end{array}$ & $\begin{array}{l}<0.2 \\
<0.2 \\
<0.2\end{array}$ \\
\hline Lactose & $\begin{array}{l}5 \cdot 0 \\
6 \cdot 5 \\
7.5\end{array}$ & $\begin{array}{l}5 \cdot 48 \\
6 \cdot 69 \\
7 \cdot 29\end{array}$ & $\begin{array}{l}46 \\
46 \\
46\end{array}$ & $\begin{array}{r}10 \cdot 1 \\
7.5 \\
9.0\end{array}$ \\
\hline D-Galactose & $\begin{array}{l}5 \cdot 0 \\
6.5 \\
7.5\end{array}$ & $\begin{array}{l}5 \cdot 41 \\
6 \cdot 69 \\
7 \cdot 25\end{array}$ & $\begin{array}{l}46 \\
46 \\
46\end{array}$ & $\begin{array}{r}2 \cdot 1 \\
10 \cdot 7 \\
13.4\end{array}$ \\
\hline
\end{tabular}

Table 3. Formation of $\beta$-galactosidase in mutants defective in lactose or galactose utilization

Experimental conditions were as described in Table $\mathrm{I}$.

\begin{tabular}{|c|c|c|c|}
\hline Strain & $\begin{array}{l}\text { Carbon } \\
\text { source }\end{array}$ & $\begin{array}{l}\text { Incubation } \\
\text { time } \\
\text { (h) }\end{array}$ & $\begin{array}{c}\text { Specific activity } \\
\text { of } \beta- \\
\text { galactosidase } \\
\text { (nmole/min/ } \\
\text { mg protein) }\end{array}$ \\
\hline $\mathrm{gal}^{+}(\mathrm{R} 2)$ & $\begin{array}{l}\text { Lactose } \\
\text { D-Galactose }\end{array}$ & $\begin{array}{l}48 \\
48\end{array}$ & $\begin{array}{l}\mathrm{II} \cdot 3 \\
\mathrm{I} \cdot 3 \cdot 2\end{array}$ \\
\hline galE34(R9) & $\begin{array}{l}\text { Lactose } \\
\text { D-Galactose }\end{array}$ & $\begin{array}{l}48 \\
48\end{array}$ & $\begin{array}{l}15.8 \\
16.0\end{array}$ \\
\hline $\begin{array}{l}\operatorname{lac}^{+}(\mathrm{RI} 43) \\
\operatorname{lac} A \mathrm{I}(\mathrm{OIO})\end{array}$ & $\begin{array}{l}\text { D-Galactose } \\
\text { D-Galactose }\end{array}$ & $\begin{array}{l}23 \\
23\end{array}$ & $\begin{array}{l}15 \cdot 4 \\
16 \cdot 2\end{array}$ \\
\hline $\begin{array}{l}\operatorname{lac}^{+}(\mathrm{R} 2) \\
\left.\operatorname{lacB}_{3}(\mathrm{OIO}) 4\right)\end{array}$ & $\begin{array}{l}\text { D-Galactose } \\
\text { D-Galactose }\end{array}$ & $\begin{array}{l}23 \\
23\end{array}$ & $\begin{array}{r}13 \cdot 0 \\
8 \cdot 8\end{array}$ \\
\hline
\end{tabular}

pH 9.0. Evidence has been presented (Gajewski et al. 1972) that lacA is impaired in lactose uptake.

\section{Mutants showing poor growth on lactose}

Twenty-nine mutants, which showed restricted but visible growth on lactose, were obtained following mutagenic treatment with NMG. All but two grew normally on glucose, galactose, or a mixture of these sugars, and these two mutants were discarded. The remainder were tested for $\beta$-galactosidase activity by colony staining after growth on glycerol + galactose, and five showed reduced staining response. Of these, only one (lacio5) did not stain at all. Mycelia of these five mutants were grown on glycerol + galactose, and assayed for $\beta$-galactosidase activity. Four contained activities 10 to $50 \%$ of wild-type and only lacios had no detectable activity; this mutant was extensively investigated. (It was described as lac5 in a preliminary report; Fantes $1972 a$.) 
Table 4. Lactose utilization, histochemical staining response, and $\beta$-galactosidase activity of progeny from the cross lac10 $5 \times$ wild-type

Growth on lactose was scored after 2 days; the histochemical stain was applied to colonies grown on the stated carbon source for 3 days. Mycelia were grown on glycerol + galactose for $24 \mathrm{~h}$ and the hydrolyses of ONPG and lactose by cell-free extracts determined. Two strains were tested from each of the four progeny classes.

\begin{tabular}{|c|c|c|c|c|c|c|}
\hline \multirow[b]{2}{*}{ Class } & \multirow{2}{*}{$\begin{array}{l}\text { No. in } \\
\text { class }\end{array}$} & \multirow{2}{*}{$\begin{array}{l}\text { Growth } \\
\text { on } \\
\text { lactose }\end{array}$} & \multicolumn{2}{|c|}{$\begin{array}{l}\text { Staining response } \\
\text { after growth on }\end{array}$} & \multicolumn{2}{|c|}{$\begin{array}{c}\text { Specific activity of } \beta \text {-galactosidase } \\
\text { (nmole } / \mathrm{min} / \mathrm{mg} \text { protein) } \\
\text { with substrates }\end{array}$} \\
\hline & & & galactose & Lactose & ONPG & Lactose \\
\hline \multicolumn{7}{|c|}{ Parental strains } \\
\hline lacros & & - & - & - & $<0.2$ & 0 \\
\hline RI 53 & & + & + & + & II $\cdot 7$ & $35 \cdot 6$ \\
\hline \multicolumn{7}{|c|}{ Progeny classes } \\
\hline I & I3 & + & - & - & $<0.2 ;<0.2$ & $3 \cdot 0 ; 6 \cdot 0$ \\
\hline II & 13 & - & + & $+*$ & $7 \cdot 9 ; \quad 7 \cdot 5$ & $22 \cdot 7 ; 19 \cdot 0$ \\
\hline III & 26 & + & + & + & $7 \cdot 5 ; \quad 10 \cdot 5$ & $I 8 \cdot 3 ; 3 I \cdot 4$ \\
\hline IV & 13 & - & - & $-*$ & $<0.2 ;<0.2$ & $3 \cdot 7 ; 5 \cdot 3$ \\
\hline
\end{tabular}

\section{Analysis of lacro5: evidence that lactose utilization is not dependent on the presence of $\beta$-galactosidase activity}

The mutant lacio5 was crossed to wild-type (RI53), and a sample of 65 progeny tested for growth on lactose, and for $\beta$-galactosidase activity by colony staining after growth on glycerol+galactose (Table 4 ). Unexpectedly, four rather than two progeny classes were obtained, the two parental classes (III and IV) and two recombinant (I and II). I grew normally on lactose but did not stain. II grew poorly on lactose but stained normally. This suggested strongly that two genes were segregating in the cross: one affecting growth on lactose and the other $\beta$-galactosidase formation. This hypothesis was confirmed by two series of further crosses. First, when the presumed single mutant types (I or II) and wild-type were crossed only one character segregated in each case. Secondly, crosses between the two types of recombinant progeny (I and II) led to independent segregation of the two characters, again giving rise to the four classes observed in the original lacro $5 \times$ wild-type cross.

The existence of a recombinant class which grew normally on lactose but apparently could not form $\beta$-galactosidase was implied by the two gene model, and this seemed at first so unlikely that a number of experiments were performed in an attempt to refute it.

Mycelia of two of each of the four progeny types were grown in liquid culture on glycerol + galactose, and their $\beta$-galactosidase activities measured. Those strains which showed a negative staining response had little $\beta$-galactosidase activity as defined by ONPG hydrolysis, whereas those showing a normal staining response also had a normal level of $\beta$-galactosidase (Table 4).

It was possible that lactose was hydrolysed by a different $\beta$-galactosidase from that detected by the staining technique or by ONPG hydrolysis, so the extracts of the progeny strains were tested for lactose hydrolysis. The results (Table 4) show that the ability to hydrolyse ONPG is coincident with the ability to release glucose from lactose. The capacity to hydrolyse lactose is not related to the ability to grow on this sugar.

The experiments described above did not prove that $\beta$-galactosidase activity was not needed for lactose utilization: it was conceivable that the absence of the activity in mycelium 


\section{Table 5. Growth and $\beta$-galactosidase activity of a bga strain with lactose as carbon source}

Cultures were grown in $\mathrm{MM}$ glucose for $12 \mathrm{~h}$, then washed with $\mathrm{MM}$ lactose and transferred to this medium for a further $18 \mathrm{~h}$ of incubation. The protein content of each culture was determined at the start and finish of the second incubation. Finally, the mycelia were harvested and assayed for $\beta$-galactosidase activity.

\begin{tabular}{|c|c|c|c|c|}
\hline \multirow[t]{2}{*}{ 車 } & \multicolumn{3}{|c|}{ Protein $/ 25 \mathrm{ml}$ culture } & \multirow{2}{*}{$\begin{array}{c}\text { Specific activity } \\
\text { of } \beta \text {-galactosidase } \\
\text { (nmole/min/ } \\
\text { mg protein) }\end{array}$} \\
\hline & $\begin{array}{c}\text { Initial } \\
(\mathrm{mg})\end{array}$ & $\begin{array}{c}\text { Final } \\
(\mathrm{mg})\end{array}$ & Final/initial & \\
\hline $\operatorname{R2I}\left(l a c^{+} ; b g a^{+}\right)$ & $\mathrm{I} \cdot \mathrm{I} 4$ & 13.5 & II $\cdot 9$ & $8 \cdot 8$ \\
\hline $9-2\left(l a c^{+} ; b g a^{-}\right)$ & $2 \cdot 9 \mathrm{I}$ & $11 \cdot 7$ & $4 \cdot 0$ & 0.6 \\
\hline
\end{tabular}

grown on glycerol + galactose would not be reflected by absence of activity after growth on lactose. To test this possibility, the 65 progeny of the cross between lacio5 and wild-type were grown on solid MM with lactose as sole carbon source, and stained for $\beta$-galactosidase activity (Table 4 ). All the $l a c^{+}$progeny showed the same staining response as when grown on glycerol + galactose, and in the majority of cases this was also true for the poorly growing $l a c^{-}$progeny. The growth of a few $l a c^{-}$segregants was too poor to allow unambiguous classification of their staining responses.

Since $\beta$-galactosidase activity is not necessary for utilization of lactose by Aspergillus nidulans, mutants unable to form the activity have been designated bga (beta-galactosidase) rather than lac. The genotype of the original mutant lacio5 is therefore lacio5;bgao. The isolation number o was assigned to this mutant as further bga mutants, $I-I_{3}$, were isolated by direct screening (see below).

\section{Physiological role of $\beta$-galactosidase}

The experiments with bgao strains indicate that $\beta$-galactosidase activity is not required for lactose utilization in Aspergillus nidulans. On the other hand, induction of the enzyme by lactose suggests that its physiological role is related to the metabolism of the sugar. Therefore conidia of wild-type, of $l a c^{+} b g a^{-}$and $l a c^{-} b g a^{+}$strains were incubated in liquid MM with lactose as carbon source. Both the wild-type and $l a c^{-}$strains grew, but in contrast to their apparently normal growth on solid MM lactose, the $b g a^{-}$strains hardly grew at all. On microscopic examination of the culture, it was found that very few $(<\mathrm{I} \%)$ of the $b g a^{-}$ conidia had germinated.

These observations suggested that $\beta$-galactosidase activity is required for germination of conidia with lactose as sole carbon source, but not for mycelial growth. Since conidia of wild-type Aspergillus nidulans can germinate and grow very feebly on agar medium without an additional carbon source, the $b g a^{-}$conidia may germinate using agar as carbon source, whereas in liquid culture germination could not occur. To test this hypothesis, conidia of a wild-type and a $b g a$ strain were allowed to germinate by incubating in liquid MM glucose for $\mathrm{I} 2 \mathrm{~h}$, and the mycelium transferred to MM lactose. The cultures were harvested after incubating for a further $18 \mathrm{~h}$, and assayed for $\beta$-galactosidase. The protein content of a sample of each culture was determined immediately after transfer and at the end of incubation in the lactose medium. The results (Table 5) show that despite the low level of $\beta$-galactosidase in the bga culture, growth on lactose occurred, and it was concluded that the primary role of $\beta$-galactosidase in $A$. nidulans is to enable conidia to germinate using lactose as carbon source. These findings again imply the existence of an alternative mode of lactose metabolism. 


\section{Table 6. Histochemical staining and $\beta$-galactosidase activities of bga mutants}

The histochemical stain was applied to colonies grown with the stated carbon source for 3 days. Mycelia were grown for $24 \mathrm{~h}$ in MM glycerol + galactose or for $42 \mathrm{~h}$ in MM lactose. Glucose was included in the latter medium at I mM to ensure germination of conidia (see text).

\begin{tabular}{|c|c|c|c|c|c|}
\hline \multirow[b]{2}{*}{ Strain } & \multicolumn{3}{|c|}{ Histochemical stain } & \multicolumn{2}{|c|}{$\begin{array}{c}\text { Specific activity of } \\
\beta \text {-galactosidase } \\
\text { (nmole } / \mathrm{min} / \mathrm{mg} \text { protein) }\end{array}$} \\
\hline & $\begin{array}{c}\text { Glycerol+ } \\
\text { galactose }\end{array}$ & Galactose & Lactose & $\begin{array}{c}\text { Glycerol + } \\
\text { galactose }\end{array}$ & Lactose \\
\hline $\mathbf{R} 2 \mathrm{I}\left(b g a^{+}\right)$ & $+t+$ & $+t+$ & +++ & $8 \cdot 6$ & $8 \cdot 6$ \\
\hline bgao & - & - & - & $<0.2$ & $<0.2$ \\
\hline bgaI & - & - & - & 0.2 & 0.7 \\
\hline bgaz & - & + & - & 0.3 & 0.8 \\
\hline$b g a_{3}$ & - & +++ & +++ & $<0.2$ & $5 \cdot 1$ \\
\hline bga4 & - & - & - & 0.3 & 0.4 \\
\hline bgas & - & $++t$ & +++ & 0.2 & $2 \cdot 6$ \\
\hline bga6 & - & - & - & 0.8 & 3.0 \\
\hline bga7 & - & - & - & $4 \cdot 7$ & I. I \\
\hline bga 8 & $(+)$ & +++ & +++ & $<0.2$ & $2 \cdot 2$ \\
\hline bgato & $(+)$ & + & + & 0.6 & $1 \cdot 3$ \\
\hline bgaII & - & $(+)$ & + & 0.6 & 1.6 \\
\hline bgaI2 & $(+)$ & ++ & ++ & $8 \cdot I$ & $7 \cdot 3$ \\
\hline bgar 3 & $(+)$ & $(+)$ & $(+)$ & I. 4 & $<0.2$ \\
\hline
\end{tabular}

To find whether the alternative mode of lactose utilization was through an extracellular $\beta$-galactosidase, the colony stain was applied to induced wild-type colonies using a range of $\mathrm{pH}$ values from 4 to 8 for the incubation buffer. Fast Black $\mathrm{K}$ was used instead of Fast Blue $\mathrm{B}$ below $\mathrm{pH} 6$. No staining of the medium surrounding the colonies was observed, and the existence of an extracellular enzyme seems unlikely.

\section{Isolation of mutants defective in $\beta$-galactosidase activity}

After mutagenesis with NMG, conidia of strain R2I were plated on MM glycerol + galactose and incubated for 4 days. The resulting colonies were stained for $\beta$-galactosidase activity, and any showing good growth but poor staining were retained. The strains were tested for growth on glucose, galactose, lactose, glycerol and glycerol + galactose. The staining response after growth on glycerol + galactose, galactose and lactose was also tested. Thirteen mutants, $b g a I-I_{3}$, were obtained, all of which grew normally on all the carbon sources tested. The mutants can be assigned to one of two classes: Class I mutants show no staining response after growth on any carbon source, whereas Class II mutants form $\beta$-galactosidase when grown on lactose, though not in response to glycerol plus galactose (Table 6). These results are in general agreement with the $\beta$-galactosidase activities in crude extracts of mycelia of the mutants after growth on the appropriate carbon source. (Cultures grown on lactose were supplemented with glucose at a concentration of $\mathrm{I} \mathrm{mM}$, to ensure germination of all strains. Growth was diauxic.)

Mutant bgaI2 was found to form $\beta$-galactosidase at a wild-type level despite its feeble staining response. The reason for this is not clear, but decreased permeability of the strain to the histochemical substrate is a possibility. This mutant and bga9 were not further analysed.

The remaining mutants were classified into Class I (bgao, I, 2, 4, 6, 7 and I3) and Class II (bga3, 5 and 8): the phenotypes of bgaro and $I I$ were intermediate. 


\section{Meiotic segregation of bga mutants}

Each mutant was crossed to wild-type (RI53) and a sample of about 90 progeny tested for $\beta$-galactosidase by the colony-staining technique after growth on glycerol+galactose or lactose. All the mutants except bgaIo and bgaII gave rise to two distinct classes of progeny. A range of phenotypes was found in the progeny of bgaro and no unambiguous classification was possible. Three classes were obtained in the cross between bgaII and wild-type in the proportion 2 wild-type: I mutant:I intermediate, suggesting that two genes were segregating. Mutants bgaIo and bgaII were not further investigated.

The remaining $b g a$ mutants showed single gene segregation when crossed to wild-type, with six mutants (and bgao) in Class I, and three in Class II. One of the main reasons for isolating mutants unable to form $\beta$-galactosidase was to obtain and identify a structural gene mutant. It is clearly impossible for a Class II mutant to be of this type as the enzymatic activity is present after growth on lactose. The nature of these mutants is discussed below. The Class I mutants, on the other hand, have the phenotype expected of a structural gene lesion, and were further investigated.

The most convenient method for grouping the mutants was by testing for close linkage. The mutants were crossed in all possible pairs, and from each cross about 100 progeny tested for $\beta$-galactosidase activity by colony staining after growth on glycerol+galactose. There were three groups within which no $\mathrm{bga}^{+}$recombinants were found, and if close linkage is taken to imply allelism three loci were involved. These presumed loci have been provisionally designated bgaA (bgao, 4, 7 and I3), bgaB (bgaI and 2), and bgaC (bga6).

\section{Identification of the structural gene for $\beta$-galactosidase}

To determine whether any of the three $b g a$ loci represented the structural gene for $\beta$ galactosidase, a number of the mutants were examined for the presence of structurally altered enzyme on the basis of altered thermolability. As the absence of $\beta$-galactosidase activity does not affect growth of the organism on lactose, temperature-sensitive growth could not be used as a diagnostic for an altered enzyme. The staining technique was modified for use at $20^{\circ} \mathrm{C}$, and several of the $b g a$ mutants appeared to be temperature-sensitive when tested. These did not, however, contain a temperature-sensitive $\beta$-galactosidase in cell-free extracts. One mutant, bgar 3 , which did not show a particularly temperature-sensitive staining response, nevertheless produced a very heat-labile $\beta$-galactosidase. (Less than $0.5 \%$ initial activity remains after $\mathrm{Io} \min$ at $40{ }^{\circ} \mathrm{C}$. Wild-type retains $70 \%$ initial activity.) It is deduced that this mutation at the $b g a A$ locus is a structural gene lesion, as presumably are the closely linked mutants bgao, 4 and 7 .

Mutant bgaAo was characterized further: mitotic haploidization located it in linkage group III. As judged by the staining technique, the mutation is recessive in diploids, and the specific activity of $\beta$-galactosidase in a heterozygous diploid $b g a^{+} / b g a^{-}$is near the mean of the values for the two homozygous diploids.

\section{Attempt to isolate mutants synthesizing $\beta$-galactosidase constitutively}

The staining technique was employed to test for $\beta$-galactosidase activity in colonies grown on solid MM plus glycerol, a carbon source which does not lead to formation of the enzyme, but which does not prevent its induction by galactose. Several mutants $(c r, 2,3$ and 79) were isolated which show a positive staining response after growth on solid MM glycerol, and these were tested for growth on glucose, galactose and lactose. The strains are phenotypically stable on vegetative transfer and were tested for $\beta$-galactosidase activity 
Table 7. Mutants giving a positive staining response for

$\beta$-galactosidase after growth on glycerol

The histochemical stain was applied to colonies after 3 days of growth. Cultures were grown for $24 \mathrm{~h}$ on glycerol or glycerol + galactose and for $42 \mathrm{~h}$ on lactose before extraction by ultrasonication.

\begin{tabular}{|c|c|c|c|c|c|c|}
\hline \multirow[b]{2}{*}{ Strain } & \multicolumn{3}{|c|}{ Staining response after growth on } & \multicolumn{3}{|c|}{$\begin{array}{c}\beta \text {-Galactosidase activity } \\
\text { (nmole/min/mg protein) } \\
\text { in mycelia grown on }\end{array}$} \\
\hline & Glycerol & $\begin{array}{c}\text { Glycerol+ } \\
\text { galactose }\end{array}$ & Lactose & Glycerol & $\begin{array}{c}\text { Glycerol+ } \\
\text { galactose }\end{array}$ & Lactose \\
\hline R2 I & - & +++ & +++ & 0.7 & 10.9 & $3 \cdot 2$ \\
\hline$c I(g ; h)$ & + & + & +++ & $<0.2$ & $<0.2$ & $2 \cdot 6$ \\
\hline$g$ & - & - & +++ & $<0.2$ & 0.8 & N.T. \\
\hline$h$ & $(+)$ & + & +++ & 0.3 & 0.7 & N.T. \\
\hline$c 2$ & ++ & +++ & N.T. & N.T. & N.T. & N.T. \\
\hline$c 3$ & + & +++ & +++ & $<0.2$ & N.T. & N.T. \\
\hline$c 79$ & $(+)$ & $(+)$ & +++ & 0.2 & 0.3 & $\mathbf{I} \cdot 9$ \\
\hline
\end{tabular}

by the staining technique and by assaying mycelial extracts after growth in liquid culture on glycerol, glycerol + galactose or lactose (Table 7). The most remarkable feature of these strains is the difference found in $\beta$-galactosidase activities between cells grown in solid or liquid culture. This was most marked for glycerol-grown cells, none of the possible constitutive mutants showing any $\beta$-galactosidase activity in crude extracts after growth in liquid culture on this carbon source. Furthermore, two mutants, $c I$ and $c 79$, appear to be noninducible by galactose, in solid or liquid culture.

The fact that growth of $c I$ on lactose leads to normal extractable levels of $\beta$-galactosidase and other evidence (Fantes, $1972 b$ ) strongly suggests that the mutant has a modified induction system rather than an enzyme with altered specificity for substrate, temperature optimum or cellular location. This strain was a double mutant from which two independently assorting characters, arbitrarily called $g$ and $h$, were isolated when $c I$ was crossed to wildtype. Strains carrying $g$ are very similar to $b g a$ Class II mutants in being inducible by lactose but not by glycerol plus galactose. Singly mutant $h$ strains stain after growth on glycerol, though not as strongly as the double mutant $g h$. This interaction is not understood.

Mutant $c 2$ showed strong staining after growth on glycerol, and this was greater when grown on glycerol + galactose. Unfortunately the strain is aconidial, and attempts to recover strongly staining conidiating recombinants from crosses to wild-type were unsuccessful. Mutant $c 3$ resembles $c 2$ in staining response but has no detectable $\beta$-galactosidase in extracts of glycerol-grown mycelium. The mutant phenotype segregates at meiosis as a single gene, unlike $c I$. Mutant $c 79$ is non-inducible by galactose, like $c r$, but the mutant phenotype is weak, and the progeny of a cross to wild-type could not be unambiguously classified. Since none of the constitutive $(c)$ mutants isolated had the desired property of forming $\beta$-galactosidase activity in mycelium grown in liquid medium in the absence of an inducer they have not been further investigated.

\section{DISCUSSION}

We have demonstrated that a second mode of lactose utilization exists in Aspergillus nidulans in addition to direct hydrolysis by $\beta$-galactosidase. This explains why no mutants have been described as being completely unable to utilize lactose for growth as a conse- 
quence of lack of $\beta$-galactosidase activity, and also the confusion in reports which only consider lactose utilization in terms of $\beta$-galactosidase activity in this organism (Gajewski et al. 1972).

The nature of the second lactose pathway is unknown, but presumably some modification of the lactose molecule occurs before cleavage of the glycosidic bond. Such a situation exists in certain Streptococcus and Staphylococcus species (McKay et al. 1969), where the hydrolytic enzyme is specific for a phosphorylated substrate. A second possibility is that lactose is oxidized prior to hydrolysis: a galactose oxidase occurs in the fungus Polyporus circinatus which has activity with lactose as a substrate, but the reaction kinetics suggest that this sugar is not a physiological substrate (Avigad, Amaral, Asensio \& Horecker, 1962).

One physiological role of $\beta$-galactosidase in Aspergillus nidulans, possibly the major one, is to enable conidia to germinate using lactose as sole carbon source. However, this does not exclude other functions for the enzyme as it is induced in mycelium on transfer from glucose to lactose (Table 5).

The finding that two molecular species of $\beta$-galactosidase occur in Aspergillus nidulans is in conflict with another report (Paszewski et al. 1970) that only one enzyme occurs. This discrepancy may be due to the different growth conditions : the enzyme preparations analysed in this study were from mycelium grown at $37^{\circ} \mathrm{C}$, whereas Paszewski grew mycelium at $3 \mathrm{I}$ to $32{ }^{\circ} \mathrm{C}$. However, the only fractionation method used by Paszewski was gel chromatography with Sephadex G-200, and the existence of two enzymes may have been overlooked.

The formation of $\beta$-galactosidase is regulated in Aspergillus nidulans, and, although no mutants known to be in specific regulatory genes have been obtained, there is some information on the physiological aspects of regulation.

A scheme for the regulation of $\beta$-galactosidase formation in Aspergillus nidulans by lactose and by galactose is offered in Fig. 4. It attempts to incorporate the ideas of two metabolic routes for lactose and also for galactose (Roberts, 1970) and their possible interrelations. It is only useful as a working hypothesis and strongly indicates the desirability of biochemical investigation of the unknown pathways.

Both lactose and galactose lead to induction of $\beta$-galactosidase in Aspergillus nidulans, and the $a$ priori deduction is that the real inducer is galactose, lactose only acting as an inducer by virtue of its hydrolysis to glucose and galactose. This reaction would be effected by $\beta$-galactosidase itself. Such a situation is comparable to that in Escherichia coli, where a trace of $\beta$-galactosidase is necessary for its own induction by lactose (Jobe \& Bourgeois, 1972). This hypothesis is unlikely for two reasons: first, the different effects of growth $\mathrm{pH}$ on induction by lactose and by galactose suggest that lactose induction is not mediated by free galactose. If this were the case, the $\mathrm{pH}$ of the medium should affect induction by either sugar to the same extent. Second, the existence of Class II bga mutants which form $\beta$ galactosidase in response to lactose but not to galactose (in the presence of glycerol) shows that induction by lactose is not dependent on inducibility by galactose. These two findings also suggest that not only the presence of galactose, but also its metabolism, is necessary for normal induction of $\beta$-galactosidase by this sugar. Since the level of $\beta$-galactosidase varies inversely with the functioning of the Leloir pathway as the $\mathrm{pH}$ is altered, this pathway cannot be responsible for induction of the activity. Normal induction found in a galactokinaseless strain supports this hypothesis.

We therefore consider the alternate galactose pathway. The metabolic route is not known, but direct oxidation was suggested by Roberts (1970), which could be by a galactose oxidase 


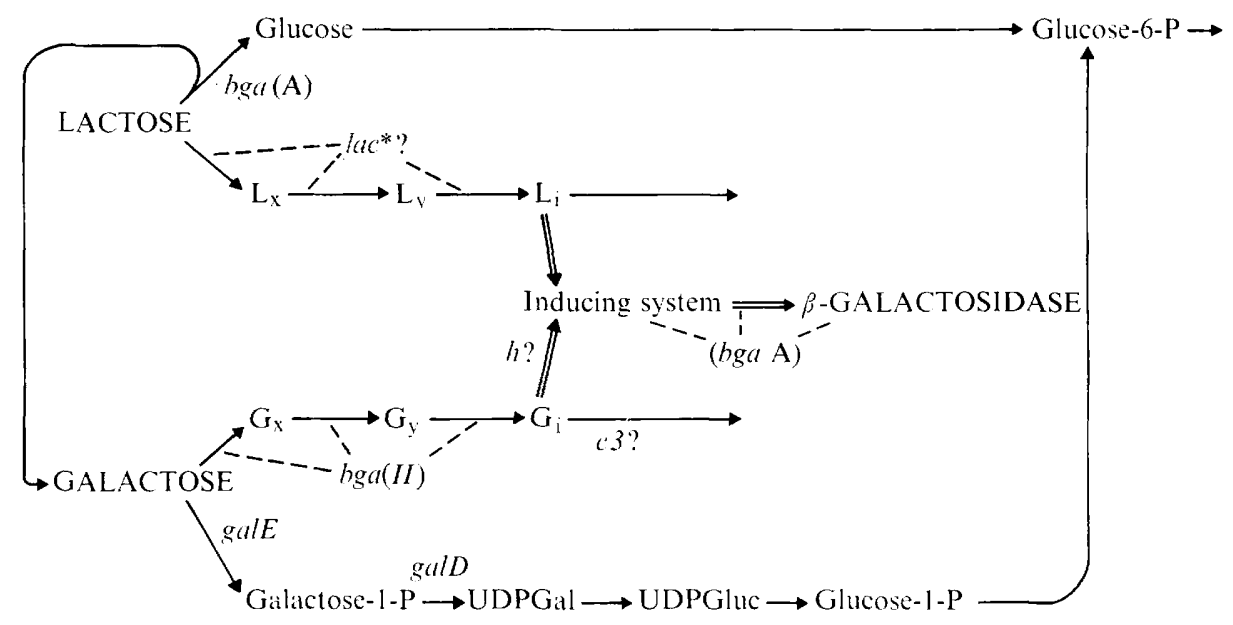

Fig. 4. Diagram of the proposed mechanism of induction of $\beta$-galactosidase in Aspergillus nidulans. Solid lines represent metabolic steps; double arrows represent control mechanisms. Mutants $l a c^{*}$ are the lac mutants of Gajewski et al. (1972) which do not form $\beta$-galactosidase activity under any induction conditions.

similar to that found in Polyporus circinatus (Avigad et al. 1962). Further evidence for the existence of a second pathway of galactose utilization comes from Katz \& Rosenberger (1970), who observed massive ${ }^{14} \mathrm{C}$ incorporation from $\left[{ }^{14} \mathrm{C}\right]$ galactose into mycelium of a transferaseless ( $\mathrm{galD}$ ) mutant, and also from Elorza \& Arst (I97I), who found that a mutant lacking phosphoglucomutase grew normally with galactose as sole carbon source. The operation of the second pathway may be necessary for induction of $\beta$-galactosidase by galactose, probably by forming the real intracellular inducer of the enzyme (see Fig. 4). This inducer may not be an intermediate of the second galactose pathway, but a compound derived from one of these intermediates. Whether the same inducer is formed from lactose by a separate metabolic route is not known, or perhaps an entirely different compound effects induction in this case. The Class II bga mutants are presumed to be defective in the second galactose pathway between galactose and the physiological inducer of $\beta$-galactosidase.

In all the mutants with an apparent constitutive phenotype ( $c$ mutants) $\beta$-galactosidase is inducible by lactose, and there is evidence that the enzyme produced by one strain ( $c r)$ is similar to that of the wild-type, so in this strain at least, the induction system must be altered. In $c I$ and $c 79 \beta$-galactosidase formation is not enhanced in the presence of galactose, whereas in $c 2$ and $c 3$ induction by galactose does occur (Fantes, 1972b). The difference in $\beta$-galactosidase formation between solid and liquid culture may be due to the presence of agar, though the mechanism by which this could affect induction is not clear. Perhaps the presence of agar allows endogenous accumulation of carbon intermediates which induce the enzyme, this accumulation not occurring in liquid culture because of dilution into the medium. Alternatively, agar (which contains galactose and galacturonic acid residues) may give rise to inducing compounds when metabolized by the mutants. The main conclusion to be drawn from the $c$ mutants isolated so far is that the system for regulation of $\beta$-galactosidase formation is complex. It is hoped that recovery of further constitutive mutants, especially if some are found to form enzyme constitutively in liquid culture, and their genetic analysis, will resolve this complexity. 
This work was supported by the Science Research Council and submitted in part fulfilment for the award of a Ph.D. to P.A.F. by the University of Leicester.

\section{REFERENCES}

Alderson, T. \& Hartley, M. J. (1969). Specificity for spontaneous and induced mutation at several gene loci in Aspergillus nidulans. Mutation Research 8, 255-264.

Avigad, G., Amaral, D., Asensio, C. \& Horecker, B. L. (1962). The D-galactose oxidase of Polyporus circinatus. Journal of Biological Chemistry 237, 2736-2743.

Barratt, R. W., Johnson, G. B. \& OGata, W. N. (1965). Wild-type and mutant stocks of Aspergillus nidulans. Genetics 52, 233-246.

Bates, W. K., Hedman, S. C. \& Woodward, D. O. (1967). Comparative inductive responses of two $\beta$ galactosidases of Neurospora. Journal of Bacteriology 93, I63I-1637.

Bates, W. K. \& WoOdWARD, D. O. (1964). Neurospora $\beta$-galactosidase: evidence for a second enzyme. Science, New York 146, 777-778.

Burstone, M. S. (1962). Enzyme Histochemistry and Its Application to the Study of Neoplasmas. London and New York: Academic Press.

Elorza, M. V. \& ARST, H. N. (I97I). Sorbose resistant mutants of Aspergillus nidulans. Molecular and General Genetics III, I85-193.

Fantes, P. A. (1972a). Lactose utilisation and $\beta$-galactosidase activity in Aspergillus nidulans. Heredity 29, I 29.

FANTES, P. A. (1972b). Studies on the $\beta$-galactosidase system in Aspergillus nidulans. Ph.D. Thesis, University of Leicester.

FoRBES, E. (1959). Use of mitotic segregation for assigning genes to linkage groups in Aspergillus nidulans. Heredity 13, 67-80.

GAJEWSKI, W. \& LitwinSKA, J. (I969). Lactose negative mutants of Aspergillus nidulans. Aspergillus Newsletter 10, 17.

Gajewski, W., Litwinska, J., Paszewskr, A. \& Chojnacki, T. (I972). Isolation and characterisation of lactose non-utilising mutants in Aspergillus nidulans. Molecular and General Genetics 116, 99-106.

$\mathrm{J}_{\mathrm{ACOB}}$, F. \& MoNOD, J. (I96I). Genetic regulatory mechanisms in the synthesis of proteins. Journal of Molecular Biology 3, 318-356.

Jobe, A. \& BourgeoIs, S. (1972). lac Repressor-Operator Interaction. VI. The natural inducer of the lac operon. Journal of Molecular Biology 69, 397-408.

Johnson, H. N. \& DeBusK, A. G. (1970). The $\beta$-galactosidase system of Neurospora crassa. II. Extracellular nature of the $\mathrm{pH} 4 \cdot 2$ enzyme. Archives of Biochemistry and Biophysics 138, 4I 2-4I7.

KATZ, D. \& Rosenberger, R. F. (1970). The utilisation of galactose by an Aspergillus nidulans mutant lacking galactose phosphate-UDP glucose transferase and its relation to cell wall synthesis. Archiv für Mikrobiologie 74, 41-51.

LHOAS, P. (1961). Mitotic haploidisation by treatment of Aspergillus niger diploids with $p$-fluorophenylalanine. Nature, London 190, 744.

Lowry, O. H., Rosenbrough, N. J., FarR, A. L. \& Randall, R. J. (195I). Protein estimation with the Folin phenol reagent. Journal of Biological Chemistry I93, 265-275.

McKay, L. L., Walter, L. A., Sandine, W. E. \& Elliker, P. R. (1969). Involvement of phosphoenol pyruvate in lactose utilisation in group N Streptococci. Journal of Bacteriology 99, 603-6ro.

Mandell, N. \& Robert, C. F. (I966). A piston extractor for the Hughes Press. Science 152, 799-800.

Martin, R. G. \& Ames, B. N. (196I). A method for determining the sedimentation behaviour of enzymes: application to protein mixtures. Journal of Biological Chemistry 236, I372-I 379.

Paszewski, A., Chojnacki, T., Litwinska, J. \& Gajewski, W. (1970). Regulation of lactose utilisation in Aspergillus nidulans. Acta biochemica polonica 17, 385-391.

Pontecorvo, G., Roper, J. A., Hemmons, L. M., MacDonald, K. D. \& Bufton, A. W. J. (1953). The genetics of Aspergillus nidulans. Advances in Genetics 5, 141-238.

RoBerTs, C. F. (1963a). The genetic analysis of carbohydrate utilization in Aspergillus nidulans. Journal of General Microbiology 31, 45-58.

ROBERTS, C. F. ( $1963 b)$. The adaptive metabolism of D-galactose in Aspergillus nidulans. Journal of General Microbiology 31, 285-295. 
ROBERTs, C. F. (1970). Enzyme lesions in galactose non-utilising mutants of Aspergillus nidulans. Biochimica et biophysica acta 201, 267-283.

SUMNER, J. B. \& GRALEN, N. (1938). The molecular weight of crystalline catalase. Journal of Biological Chemistry 125, 33-40.

WALLENFELS, K. (1962). $\beta$-Galactosidase. In Methods in Enzymology, vol. V. Edited by S. P. Colowick and N. O. Kaplan. New York and London: Academic Press. 